\title{
LA GLOBALIZACIÓN Y SU IMPLICANCIA EN EL CONTROL Y GESTIÓN
}

\author{
Dr. JULIO V. FLORES KONJA (*) \\ Mg. ADRIÁN A. FLORES KONJA (*)
}

\section{INTRODUCCIÓN}

La globalización implica "considerar el mundo como el mercado, fuente de insumos y espacio de acción, tanto para la producción como para adquisición y la comercialización de productos". Algunas de las características de la globalización serían, por ejemplo, el aumento del comercio exterior y de la exportación de capitales, la innovación tecnológica, etc.

Bajo este contexto, es importante que las empresas realicen una adecuada utilización de los recursos humanos, técnicos y financieros para obtener bienes y servicios de mejor calidad y al menor precio posible, a fin de ser más competitivos y cumplir con la misión, los objetivos y los planes de la empresa.

En este mundo globalizado, el control interno es una herramienta fundamental porque ayuda a conseguir las metas y evitar fallas y sorpresas a lo largo del camino. Pero el control interno no puede cambiar por sí mismo una pobre administración en una buena, ni cambiar las políticas o programas de gobierno, las acciones de los competidores o las condiciones económicas a través del control de gestión. El control interno no asegura el éxito o la supervivencia. Un sistema de control interno, por más bien concebido y operado que fuera, proporciona sólo razonable -no absolutamente- pro- mesas de buena gestión y la sugerencia relacionada a los logros de los objetivos de una entidad. Estas incluyen los errores de adopción de medidas que pueden ser defectuosas y originan sustracciones por error osimple equivocación. Adicionalmente, los controles pueden ser superpuestos por la colusión de dos o más personas y la gestión tiene la capacidad para rechazar el sistema.

\section{ASPECTOS RELACIONADOS CON EL CONTROL Y GESTION}

Control.- Comprende las acciones orientadas a cautelar en forma previa, durante la gestión y a su verificación posterior de la correcta captación y utilización de recursos humanos, materiales y financieros.

Control interno.- Es un proceso, efectuado por la alta Dirección de una entidad, administrativos y otro personal, diseñado para proporcionar información razonable, relacionado al alcance de los objetivos siguientes:

- Efectividad y eficiencia de operaciones.

- Confiabilidad del informe financiero y de gestión.

- Cumplimiento de normas internas y dispositivos legales aplicables.

La primera categoría se aplica a los objetivos básicos de la entidad, incluyendo 
le economicidad y desempeño, salvaguardando los recursos. La segunda categoría se refiere a la preparación de declaraciones financieras y de gestión confiables, mientras que la tercera, se relaciona al cumplimiento de las leyes que la entidad debe respetar.

\section{COMPONENTES DE LA ESTRUCTURA DE CONTROL INTERNO}

1. Ambiente de control.- Establece la tónica de una organización al influenciar el conocimiento de control de su gente; es decir, la honradez, competencia y valores éticos del personal; la filosofía de gestión y estilo de operación; la gestión y el modo que se asigna la autoridad, la responsabilidad, organización y desarrollo de su gente, atención y la Dirección proporcionada por la Alta Dirección; en consecuencia el control asegura el cumplimiento de metas y objetivos.

2. Evaluación de riesgo.- Cada entidad afronta una variedad de riesgos desde fuentes externas e internas que deben analizarse para lograr los objetivos planteados.

- $\quad$ Riesgo inherente.- La posibilidad o susceptibilidad de que ocurran errores o irregularidades significativas antes de considerar la efectividad de los sistemas de control. Está totalmente fuera de control por parte del Auditor, porque es propio de la operación del ente.

- $\quad$ Riesgo de control.- El peligro de que los controles internos no detecten o eviten errores e irregularidades significativas en forma oportuna.

- $\quad$ Riesgo de detección.- El riesgo de que los procedimientos de auditoría seleccionados no detecten errores o irregularidades significativas.
3. Control de actividades de gestión.- Son políticas y procedimientos que aseguran que las directivas de gestión sean llevadas a cabo. Las actividades de control ocurren a lo largo de la organización, en todos los niveles y funciones. Incluye una gama de actividades tan diversas como aprobaciones, autorizaciones, comprobaciones, conciliaciones, revisiones de desempeño, segregación de deberes, entre otros.

4. Información y comunicación.- La información pertinente debe ser identificada, captada y comunicada en una forma y plazo de tiempo que permita a la gente asumir sus responsabilidades. La comunicación efectiva tiene que ocurrir en un sentido más amplio, fluyendo por toda la organización.

5. Control o vigilancia.- Es necesario un proceso que evalúa la calidad de desempeño del sistema de control interno a través del tiempo. Las mediciones se realizan mediante actividades en proceso de verificación, evaluaciones separadas o una combinación de ambos.

El sistema de control interno se entreteje con las actividades operativas del ente y por razones fundamentales de la empresa. El control interno es muy efectivo cuando los controles se basan en la infraestructura de la entidad y son una parte de la esencia de la empresa; es decir, son estructurados para apoyar la calidad y las iniciativas de fortalecimiento, evitando costos innecesarios y posibilitando respuestas rápidas en condiciones cambiantes.

\section{MODALIDADES DE LA FUNCIÓN DE CONTROL}

Durante el desarrollo y culminación de los actos administrativos existe el control previo, control concurrente y control posterior. 
- Control previo.- Es el examen de las operaciones propuestas antes de la autorización para que el acto administrativo surta efectos, con el propósito de establecer su propiedad, legalidad, veracidad y conformidad. Por ejemplo, existe la necesidad de adquirir un bien o servicio, lo cual deberá contar con asignación presupuestaria y estar considerado dentro del cuadro de necesidades.

- Control concurrente.- Es el que se aplica conjuntamente a la realización de las operaciones cuya corrección se está verificando. Por ejemplo, si la compra es por adjudicación directa, deberá contar con tres cotizaciones, dependiendo del precio; y para el giro del cheque, con la factura, orden de compra, guía de remisión, la conformidad de ingreso al almacén en buenas condiciones del bien adquirido.

- Control posterior.- Está referido a todos aquellos procedimientos administrativos diseñados con el propósito de cautelar el correcto cumplimiento de las condiciones señaladas en las normas internas y de acuerdo a ley, con posterioridad a los actos propios de la ejecución. Por ejemplo, este control se puede realizar después de varios meses o al finalizar el año, en la cual verificaremos si la compra ha cumplido con las exigencias necesarias.

En conclusión, diremos que el control interno ayuda a una entidad a alcanzar sus logros de desempeño y economicidad, prevenir la pérdida de recursos y asegurar informes financieros confiables. Asimismo, preserva o resguarda que las entidades públicas y privadas cumplan con las leyes y regulaciones, evitando daños a su reputación y otras consecuencias.

Gestión. -Es la aplicación de métodos, técnicas e instrumentos administrativos en el proceso de obtención, utilización y mantenimiento de los medios necesarios para la rea- lización de las acciones que concreten las metas y los objetivos previamente definidos.

Gestión administrativa.- Es el conjunto de acciones mediante los cuales el directivo desarrolla sus actividades a través del cumplimiento de las fases del proceso administrativo: planear, organizar, dirigir, coordinar y controlar.

Gestión financiera.- En el ámbito de la actividad privada es el reto que se lleva a cabo para la toma de decisiones y corresponde asumirlo tomando en cuenta los siguientes aspectos:

- Decisión de inversión.- Trata del estudio y análisis de la forma en que conviene analizar las situaciones en cuanto a la oportunidad, eficiencia y eficacia. Generalmente, la inversión está orientada al incremento del activo fijo.

- Decisiones de financiamiento.Consiste en la elección de recursos financieros que la empresa obtenga durante un período, que pueden ser recursos propios o recursos de endeudamiento.

- Decisión de reparto de utilidad.Consiste en distribuir oportuna y eficazmente los recursos obtenidos al cierre del ejercicio. La oportunidad consiste en distribuirlas en el momento que más se necesita, la eficacia se refiere a la prontitud de su distribución y la eficiencia consiste en la distribución adecuada de la utilidad.

Gestión financiera del Estado.- Es el proceso por el cual se llevan a cabo las diversas acciones encaminadas a la obtención de los fondos públicos, y disponer de ellos al utilizarlos en la adquisición de los bienes y servicios indispensables para la atención de las necesidades públicas, en el marco de una 
determinada política general de gobierno y sujetos a cierto régimen normativo.

Gestión pública.- Es el conjunto de acciones que permite a las entidades públicas lograr sus fines, objetivos y metas en el marco de una determinada política de gobierno.

\section{SISTEMA DE CONTROL DE GESTIÓN}

Es la evaluación de la gestión en función de los objetivos trazados y los resultados obtenidos con relación a los recursos asignados y al cumplimiento de los programas y planes de la entidad examinada; es decir, si hubo una adecuada utilización de los recursos humanos, técnicos y financieros (eficiencia), la forma inteligente de emplear los fondos para obtener bienes y servicios de la mejor calidad y al menor precio posible (economía) y el grado en que se cumplen la misión, los objetivos y los planes (eficacia).

El objetivo del sistema de control de gestión es identificar oportunamente los obstáculos que afronta el plan estratégico en el logro de los objetivos y metas propuestas, para plantear soluciones lógicas y razonables.

En la actualidad, observamos que por falta de control de la gestión viene creciendo el concepto de que el bien que debo hacer no es el colectivo, sino, el personal. Esto introduce en la sociedad el enriquecimiento ilícito a través del fraude, el engaño, el robo, el soborno, la extorsión, el peculado, la evasión, el contrabando, la violencia y otras acciones que integran el término corrupción. Por ello, es indispensable diseñar un plan estratégico para mantener los valores morales e incorporar la eficiencia a la cultura empresarial en todos los ámbitos del sector público y privado.

Finalmente, un Plan Nacional para combatir la corrupción se debe basar, primordialmente, en el despertar de la conciencia moral y en la implantación de sistemas eficientes de evaluación de gestión como una obligación legal de la dirección y administración de los entes públicos $\mathrm{y}$ privados; considerando las siguientes acciones:

1. Programa orientado a despertar la conciencia moral entre todos los ciudadanos.

2. Leyes, normas y políticas que exijan el establecimiento de sistemas eficientes de control de gestión e informes públicos sobre los resultados de los entes del sector público y privado. Las leyes deben considerar sanciones ejemplarizantes para que la corrupción no sea una práctica fácil y productiva.

3. Inclusión de los componentes y elementos de la estructura básica del sistema de control de gestión en las leyes comerciales y las normas de control de los entes públicos y privados.

4. Diseminación, al nivel apropiado en los entes del sector público y privado, del marco conceptual de control de gestión, mediante conferencias, seminarios y publicaciones.

5. Auditorías integrales para evaluar la gestión de los directivos y administradores, el incumplimiento de las leyes, reglamentos y normas contractuales, y para comprobar la razonabilidad de los informes financieros y de resultados de gestión.

6. Financiamiento e implementación de estrategias con apoyo de organismos internacionales y nacionales. 
BIBLIOGRAFÍA

BRAVO CERVANTES, Miguel H.

1998. "Auditoría integral".

BROWN, Gerard

"El diagnóstico de la empresa".

SLOSSE, Carlos y otros.

1995. "Auditoría un nuevo enfoque empresarial".

Diversas Normas del Sistema Nacional de Control. 